\title{
ASPECTOS ECONÔMICOS DOS PLANTIOS COM EUCALIPTO (Eucalyptus spp.) NA REGIÃO DO BAIXO ACRE
}

\author{
Alisson Maia de Queiroz ${ }^{1}$, Zenóbio Abel Gouvêa Perelli da Gama e Silva ${ }^{2}$ \\ ${ }^{1}$ Universidade Federal do Acre, Programa de Pós-Graduação em Desenvolvimento Regional, Rio Branco, Acre, Brasil - \\ alisson.florestal@gmail.com \\ ${ }^{2}$ Universidade Federal do Acre, Centro de Ciências Biológicas e da Natureza, Rio Branco, Acre, Brasil - zenobiosilva@hotmail.com
}

Recebido para a publicação: 01/09/2015 - Aceito para a publicação: 24/06/2016

\begin{abstract}
Resumo
O objetivo desse artigo foi, ao gerar informações econômicas sobre a atividade de reflorestamento com Eucalyptus spp., no estado do Acre, subsidiar a formulação de políticas públicas voltadas à utilização dos recursos florestais locais. Em termos específicos, essa pesquisa visou: (a) identificar os custos relacionados à implantação e manutenção de povoamentos de eucalipto na região do Baixo Acre; (b) quantificar as receitas da atividade de reflorestamento nessa região; e (c) avaliar a viabilidade econômica de povoamentos florestais na região. O método utilizado identificou o valor presente líquido (VPL), a taxa interna de retorno (TIR) e o valor esperado da terra (VET), válidos para os povoamentos com eucalipto nessa região. Dos resultados gerados pode-se inferir que: (a) os projetos analisados apresentaram um elevado custo de implantação e manutenção quando comparados com os custos encontrados em outros estudos; (b) os reflorestamentos avaliados geraram uma renda menor que as obtidas em projetos similares implantados em outras regiões do Brasil; e (c) os povoamentos pesquisados demonstram que, nas condições propostas, produzir eucalipto para atender à geração de energia em Rio Branco não oferece viabilidade superior ao custo de oportunidade do capital, indicando assim a inviabilidade econômica dessa atividade.
\end{abstract}

Palavras-chave: Reflorestamento; custos de produção; estado do Acre.

\begin{abstract}
Economic aspect of eucalyptus plantation (Eucaliyptus ssp.) in Baixo Acre region. The objective of this paper was, by generating economic information about the reforestation activity with Eucalyptus spp. in the state of Acre, to subsidize the formulation of public policies for the use of local forest resources. Specifically, this research sought to: (a) identify the costs related to the implementation and maintenance of eucalyptus stands in Baixo Acre; (b) quantify the revenue of the reforestation activity in that region and (c) assess the economic viability of forest plantations in this region. The method identified the net present value (NPV), internal rate of return (IRR) and the expected value of land (VET), valid for eucalyptus plantations in this state. From the results generated, it was possible to conclude that: (a) the projects analyzed showed a high cost of implementation and maintenance when compared with the costs found in other studies; (b) the assessed reforestation generated a lower income than those obtained in similar projects implemented in other regions of Brazil and (c) the surveyed plantations demonstrate that, under the proposed conditions, produce eucalyptus to meet the Rio Branco in power generation does not offer greater viability to the opportunity cost of capital, thus indicating the economic infeasibility of this activity.
\end{abstract}

Keywords: Reforestation; production costs; State of Acre.

\section{INTRODUÇÃO}

A atividade de reflorestamento no Brasil foi desenvolvida a partir do aumento do desmatamento e da pressão política pela busca de fontes alternativas de matérias-primas para indústrias intensivas em recursos naturais (BRASIL, 2007).

Karling (2004) afirma que o Brasil dispõe de características de solo e clima favoráveis ao plantio de florestas e tem uma extensão significativa de terras aptas à produção de espécies florestais. Assim sendo, a implementação de tais reflorestamentos poderia não só suprir a necessidade de consumo interno, como também fazer o país passar a ocupar uma posição importante no cenário mundial como produtor de madeira advinda de florestas plantadas.

Fischer e Zylbersztajn (2012) acrescentam que a indústria de base florestal no Brasil tem se tornado cada vez mais dependente da silvicultura para o suprimento de matéria-prima, substituindo a madeira oriunda de 
florestas nativas. Essa gradativa substituição está relacionada principalmente às limitações naturais e técnicas, além das restrições ambientais para a utilização de florestas nativas.

Cabe aqui mencionar que Poggiani (1979) argumenta que não faria sentido proibir a derrubada de matas nativas se não houvesse a possibilidade de utilizar madeira proveniente de povoamentos florestais. $\mathrm{O}$ autor complementa que é evidente que a floresta natural não oferece apenas madeira: ela disponibiliza uma grande quantidade de benefícios incalculáveis, de modo que o incentivo à atividade de reflorestamento não tem o objetivo de diminuir a importância da preservação das florestas naturais, mas apenas de demonstrar como o cultivo intensivo de árvores é indispensável para diminuir a intensidade de devastação das matas nativas.

Já Bentes-Gama (2005) argumenta que o uso de matéria-prima madeireira proveniente de florestas plantadas é uma estratégia importante no sentido de promover a conservação ambiental em áreas da região amazônica alteradas pela agricultura e pecuária.

Em termos de reflorestamento, Ferreira e Silva (2004) revelam que no final da década de 70 foram realizados trabalhos científicos que recomendavam o uso de algumas espécies de eucaliptos para a região amazônica, baseados em dados climáticos e no comportamento dessas espécies em condições edafoclimáticas semelhantes.

Contudo, para a efetiva implantação de projetos de reflorestamento, torna-se necessária a realização de avaliações econômicas de tais projetos. Tal afirmação se embasa em Klemperer (1996), o qual comenta que para a implantação de um projeto, seja ele florestal ou não, é necessário que se faça um investimento e, geralmente, o capital a ser usado nesse processo é escasso, existindo muitos usos possíveis competindo por ele. Assim, é imprescindível que seja feita uma gestão adequada desse capital, para que possa ser investido em projetos economicamente atrativos. Rapassi et al. (2008) complementam que o sucesso de um projeto está sujeito à sua avaliação prévia, de modo que isso leva ao planejamento das atividades, para maximizar a produtividade e minimizar os custos de produção.

Nesse contexto, tem-se que o setor florestal se caracteriza por apresentar retornos financeiros em longo prazo, fazendo com que esse tipo de investimento no setor seja um grande entrave a novos negócios. Assim, os produtores rurais que tiverem interesse em investir em projetos florestais precisam ficar atentos à avaliação econômico-financeira desses projetos. Essa avaliação demanda a utilização de critérios e técnicas de análise que permitem decidir se o projeto deve ser colocado em prática (SANT’ANNA; LEONEL, 2009).

Diversos trabalhos, como, por exemplo, o de Karling (2004), Saguino (2009), Berger et al. (2011) e Fiedler et al. (2011), entre outros, têm abordado a viabilidade econômica de povoamentos florestais. Porém vale ressaltar que esses estudos são realizados, principalmente, nas regiões Sul e Sudeste do Brasil, onde as indústrias demandantes de madeira e o setor florestal estão bem estabelecidos. Dessa forma, a região Norte, especialmente o estado do Acre, ainda possui poucos trabalhos nesse tema quando comparada com outras regiões do país.

Considerando as características do estado do Acre, tais como a infraestrutura local e a disponibilidade de terras com preços baixos, além da existência do baixo custo com mão de obra, justificam-se estudos científicos relacionados à atividade de reflorestamento na região.

Diante do exposto, o objetivo deste artigo foi, ao gerar informações econômicas sobre a atividade de reflorestamento com Eucalyptus spp. no estado do Acre, contribuir com as políticas públicas voltadas ao setor florestal local. Em termos específicos, esta pesquisa visou: (a) identificar os custos relacionados à implantação e manutenção de povoamentos de eucalipto no Acre; (b) quantificar as receitas da atividade de reflorestamento nesse estado; e (c) verificar a viabilidade econômica de povoamentos florestais na região.

\section{MATERIAL E MÉTODO}

A área de estudo escolhida para essa pesquisa foi a regional do Baixo Acre, onde estão situados os municípios de Rio Branco (capital do estado) e Senador Guiomard. A escolha desse local se deu pelo fato de que os primeiros povoamentos de eucalipto do estado do Acre se localizam nos referidos municípios. O estado do Acre e seus respectivos municípios podem ser observados na figura 1.

Conforme sugere Klemperer (1996), foram coletados dados sobre custos e receitas inerentes às etapas de implantação e condução dos projetos de reflorestamento em análise. Tal coleta ocorreu em uma firma instalada em Rio Branco, capital do estado do Acre, que vem realizando trabalhos experimentais visando verificar a adaptação e o comportamento de algumas espécies de eucalipto em regime de monocultura na região. Saliente-se que tais dados se referem ao período 2012-13, advindos de povoamentos de eucalipto implantados em 10 áreas (que somam 30 hectares) no ano de 2012.

Ainda sobre os valores coletados, eles dizem respeito a uma quantia média gasta para a implantação e manutenção de um hectare de eucalipto em um espaçamento de 3,0 x 3,0 m, com corte raso aos 7 anos e com intenção de utilizar a madeira para fins energéticos (lenha). 


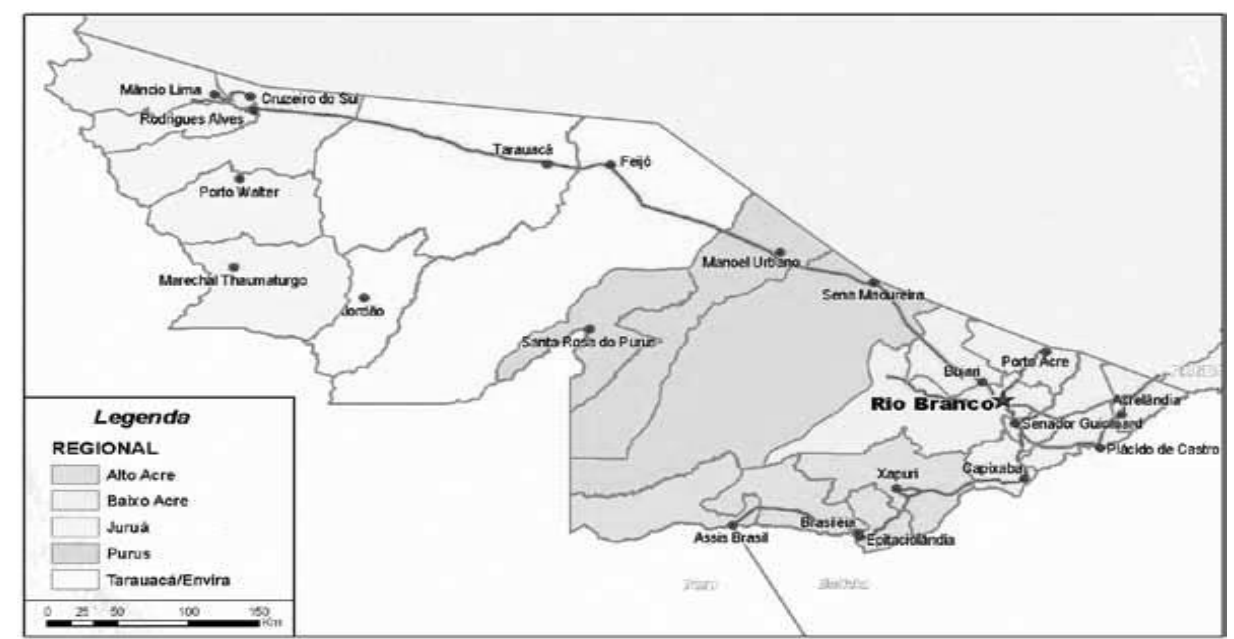

Fonte: ACRE (2010).

Figura 1. Regionais de desenvolvimento do estado do Acre.

Figure 1. Regional of development from the State of Acre.

Saliente-se que o levantamento dos custos, como sugere Silva et al. (2005), foi feito conforme a composição da sequência de operações necessárias para a implantação e condução do referido povoamento florestal. Portanto foram consideradas as despesas referentes ao planejamento, controle de formigas, limpeza da área, preparo do solo, plantio, manutenção e aquisição de insumos.

Na tabela 1 são apresentados todos os itens de custo considerados pela firma de reflorestamento para a implantação e condução do povoamento de eucalipto em análise.

Tabela 1. Itens de custo dos povoamentos de eucalipto, Baixo Acre, 2013 (R\$/ha).

Table 1. Cost items with eucalyptus plantation in Baixo Acre, State of Acre, 2013 (R $\$ / \mathrm{ha})$.

\begin{tabular}{lrrlrc}
\hline Item de custo (Serviços) & Total & \multicolumn{1}{c}{$\%$} & Item de custo (Insumos) & Total & \% \\
\hline Demarcação da área & 212,00 & 4,40 & Mudas & 733,20 & 25,82 \\
Aplicação de formicida & 400,00 & 8,29 & Gesso (Ca) & 318,00 & 11,20 \\
Retirada da vegetação & 285,00 & 5,91 & Adubação de base (superfosfato) & 560,00 & 19,72 \\
Aplicação de herbicida & 130,00 & 2,70 & Adubação de plantio (6-30-6) & 330,15 & 11,62 \\
Subsolagem & 373,00 & 7,73 & Adubação de cobertura (18-0-18) & 496,00 & 17,46 \\
Gradagem & 203,00 & 4,21 & Formicida & 198,00 & 6,97 \\
Calagem & 180,00 & 3,73 & Herbicida & 204,80 & 7,21 \\
Adubação de base & 233,00 & 4,83 & & & \\
Abertura de covas e plantio & 233,00 & 4,83 & & & \\
Adubação de plantio & 116,00 & 2,41 & & \\
Roçada, capina e coroamento & $1.620,00$ & 33,59 & & \\
Adubação de cobertura & 360,00 & 7,46 & & $\mathbf{2 . 8 4 0 , 1 5}$ \\
Monitoramento & 477,84 & 9,91 & $\mathbf{1 0 0 , 0 0}$ \\
\hline Total (Serviços) & $\mathbf{4 . 8 2 2 , 8 4}$ & $\mathbf{1 0 0 , 0 0}$ & Total (Insumos) & \\
\hline F & & & & \\
\hline
\end{tabular}

Fonte: Levantamento de campo realizado pelos autores.

Complementando as informações indicadas nessa tabela, é oportuno mencionar que as espécies usadas nos reflorestamentos analisados neste estudo foram Eucalyptus urophila e Eucalyptus camaldulensis. Cabe salientar que nos projetos avaliados não foram aplicados micronutrientes.

Em termos de renda, foi utilizado o valor de $\mathrm{R} \$ 15,00 / \mathrm{m}^{3}$, o qual representa o preço médio praticado no mercado de Rio Branco para a lenha em pé na floresta, no ano de 2015. Já o valor considerado para a compra e venda da terra foi de $\mathrm{R} \$ 5.000,00 /$ ha, que é um valor médio praticado no mercado imobiliário dessa região. Para efeito de comparação, nos resultados foram considerados dois cenários: no primeiro (com a terra) houve a compra da terra no ano zero e a venda no ano 7; e no segundo cenário (sem a terra) não houve custo para a aquisição da terra.

Complementando, devido ao fato de os povoamentos estudados terem sidos implantados nos anos de 2012 e 2013, eles ainda não tinham sido explorados quando da coleta de dados para este estudo, assim como não foram encontradas, na literatura, informações sobre a produtividade do eucalipto no estado do Acre. Assim 
sendo, foi utilizado o incremento médio anual (IMA) de 40,7 m³/ha/ano, divulgado por ABRAF (2013) e válido para povoamentos de eucalipto no Brasil. Com isso, tem-se uma projeção do volume total de $284,9 \mathrm{~m}^{3} / \mathrm{ha}^{2}$ quando esses reflorestamentos alcançarem a sua idade de corte, o que ocorrerá em 2019 e 2020, quando tiverem sete anos de idade.

Identificação e quantificação dos custos de produção da atividade de reflorestamento no Baixo Acre

Conforme sugerem Berger et al. (2002), para identificar e quantificar os custos de implantação e custos de manutenção dos plantios de cada área, foi empregada a Equação1:

$$
C_{n}=\sum_{i=0}^{n}\left(C_{i}+C_{m}\right)
$$

em que: $\mathrm{Cn}=$ custo total dos povoamentos (R\$/ha); $C_{\mathrm{i}}=$ custos com implantação dos povoamentos $(\mathrm{R} \$ / \mathrm{ha})$; $C_{\mathrm{m}}=$ custo de manutenção dos povoamentos (R $\left.\$ / \mathrm{ha}\right)$.

\section{Quantificação das receitas da atividade de reflorestamento no Baixo Acre}

Na quantificação da receita dos reflorestamentos em análise, como indicado por Berger e Garllipp (1982), adotou-se a Equação 2:

$$
R_{n}=V_{n} \quad x \quad P
$$

em que: $R_{n}=$ receita bruta total com a venda da madeira $(R \$ / h a) ; V_{n}=$ volume total da produção no ano $n$ $\left(\mathrm{m}^{3} / \mathrm{ha}\right) ; \mathrm{P}=$ preço da madeira a ser vendida para a produção de biomassa $\left(\mathrm{R} \$ / \mathrm{m}^{3}\right)$.

\section{Avaliação da viabilidade econômica de povoamentos florestais no Baixo Acre}

Para avaliação da viabilidade econômica dos projetos abordados, foram adotados conceitos indicados por Karling (2004), Silva e Fontes (2005), Rezende e Oliveira (2008), Berger et al. (2011) e Souza Junior (2012). Assim, fez-se uso dos critérios Valor Presente Líquido (VPL), Taxa Interna de Retorno (TIR) e Valor Esperado da Terra (VET), os quais são apresentados a seguir, com suas respectivas fórmulas:

\section{Valor Presente Líquido (VPL)}

Por sugestão de Rezende e Oliveira (2008), no cálculo do Valor Presente Líquido (VPL) foi adotada a seguinte equação:

$$
V P L=\sum_{j=0}^{n} R_{j}(1+i)^{-j}-\sum_{j=0}^{n} C_{j}(1+i)^{-j}
$$

em que: $R_{j}=$ receitas no período de tempo $\mathrm{j}$ considerado; $C_{j}=$ custos no período de tempo $\mathrm{j}$ considerado; $\mathrm{n}=$ duração do projeto em anos ou em número de períodos de tempo; $\mathrm{i}=$ taxa anual de juro, expressa de forma decimal.

Seguindo proposta de Rezende e Oliveira (2008), os projetos analisados seriam viáveis e, portanto aceitos, caso seu VPL fosse maior que zero.

Taxa Interna de Retorno (TIR) Equação 4:

No cálculo da Taxa Interna de Retorno (TIR), seguindo Rezende e Oliveira (2008), foi utilizada a

$$
T I R=\sum_{j=0}^{n} R_{j}(1+i)^{-j}-\sum_{j=0}^{n} C_{j}(1+i)^{-j}=0
$$

em que: $\mathrm{R}_{\mathrm{j}}=$ receitas do período de tempo $\mathrm{j}$ considerado; $\mathrm{C}_{\mathrm{j}}=$ custos do período de tempo $\mathrm{j}$ considerado; $\mathrm{n}=$ duração do projeto em anos ou em número de períodos de tempo.

\section{Valor Esperado da Terra (VET)} Equação 5:

O Valor Esperado da Terra (VET), como sugerem Silva e Fontes (2005), foi obtido mediante o uso da

$$
V E T=\frac{\sum_{n}^{t}\left(R_{n}-C_{n}\right) \times(1+i)^{t-n}}{\left((1+i)^{t}-1\right)}
$$


em que: $R_{n}=$ receita no ano de ocorrência; $C_{n}=$ custo no ano de ocorrência; $n=$ ano de ocorrência; $i=$ taxa de juros; $\mathrm{t}$ = rotação.

É oportuno mencionar que, seguindo os conceitos do Valor Esperado da Terra, no cálculo da Equação 5 não foi considerado o valor da terra como custo no ano zero, nem como renda advinda de sua revenda no ano sete desses projetos.

Complementando, para efeito de comparação, os resultados foram considerados sob dois cenários. Mais especificamente, em um cenário foi considerada a inclusão, no fluxo de caixa do projeto, do fator terra como custo no ano zero e renda no sétimo ano, e outro cenário, o fluxo de caixa não levou em conta a terra como custo nem como renda, nos anos zero e sete, respectivamente. Esses valores estão indicados nas tabelas que apresentam os resultados desse estudo.

\section{Análise de sensibilidade}

Na realização deste estudo, foram feitas análises de sensibilidade visando avaliar o comportamento dos valores obtidos sob diferentes taxas de juro adotadas, custos de produção e níveis de produção e de preço.

Como ponto de partida, na escolha das taxas de juros adotadas foi levado em conta o estudo de Lima Junior et al. (1997), os quais descrevem que tais juros, para analisar projetos florestais no Brasil, situam-se entre 6 e $12 \%$ ao ano. Assim sendo, para efeito de comparação do comportamento dos valores obtidos em função de diferentes taxas, foram adotadas as taxas de 6, 8, 10 e $12 \%$ ao ano.

Em termos do comportamento dos valores dos custos operacionais gerados nesse estudo, pressupôs-se variarem para menos, em 5, 10, 15 e 20\% em relação ao custo básico calculado, mantendo-se a produtividade e o preço constantes. Já no tocante à receita, considerou-se um aumento em 5, 10, 15 e 20\% em relação à receita calculada inicialmente nesse estudo, mantendo-se constante o custo calculado nessa pesquisa. Salienta-se que, nessas duas situações, na variação nos custos e nas rendas, foi considerado que a produtividade, o valor médio apresentado por ABRAF (2013), se manteria constante.

\section{RESULTADOS E DISCUSSÃO}

\section{Identificação e quantificação dos custos de produção da atividade de reflorestamento}

A tabela 2 indica os custos com serviços e com insumos, distribuídos anualmente durante o período de duração do projeto.

Tabela 2. Custos anuais com serviços e insumos dos povoamentos de eucalipto no Baixo Acre, 2013 (R $\$ / h a)$.

Table 2. Annual costs of services and inputs with eucalyptus plantation in Baixo Acre, State of Acre, 2013 (R\$/ha).

\begin{tabular}{|c|c|c|c|}
\hline Ano & Serviços & Insumos & Total \\
\hline 0 & $3.354,73(1)$ & $2.335,75(1)$ & $5.690,48(1)$ \\
\hline 1 & $809,73(1)$ & $372,40(1)$ & $1.182,13(1)$ \\
\hline 2 & $109,73(1)$ & $22,00(1)$ & $131,73(1)$ \\
\hline 3 & $109,73(1)$ & $22,00(1)$ & $131,73(1)$ \\
\hline 4 & $109,73(1)$ & $22,00(1)$ & $131,73(1)$ \\
\hline 5 & $109,73(1)$ & $22,00(1)$ & $131,73(1)$ \\
\hline 6 & $109,73(1)$ & $22,00(1)$ & $131,73(1)$ \\
\hline 7 & $109,73(1)$ & $22,00(1)$ & $131,73(1)$ \\
\hline Custo total & $4.627,66(2)$ & $2.789,12(2)$ & $7.416,79(2)$ \\
\hline
\end{tabular}

Verifica-se nessa tabela que o custo com serviços e o custo com insumo respondem, respectivamente, por $62,39 \%$ e $37,60 \%$ do valor presente do custo total de produção.

Cabe salientar que Silva et al. (2004) constataram que o custo médio para implantação de um povoamento de eucalipto em Brasília, DF, foi de R\$ 703,02/ha. Já Fiedler et al. (2011), estudando os custos de implantação e manutenção de povoamento de eucalipto, concluíram que, do custo total de implantação e manutenção no primeiro ano do plantio, 34,81\% são custos com serviços e 65,19\% com insumos. Melido (2012), avaliando dois projetos florestais com eucalipto para fins energéticos, constatou que foram gastos em média $\mathrm{R} \$ 4.621,94 /$ ha na primeira rotação com corte efetuado aos 6 anos, e os custos de implantação foram de $\mathrm{R} \$ 2.483,30 /$ há, que correspondem a 53,7\% das despesas decorrentes da primeira rotação do projeto estudado.

Como se observa, o custo médio encontrado nesta pesquisa é elevado em comparação ao valor obtido 
em outros estudos. Assim, cabe aqui mencionar que Berger e Garlipp (1982) explicam que essa diferença de custos médios é fruto das diferenças fisiográficas e particularidades que cada região tem para implantação de projetos na área de reflorestamento. Carmo et al. (2011) complementam explicando que a definição dos procedimentos silviculturais e insumos necessários para o desenvolvimento satisfatório do reflorestamento refletem em custos que dependem das características econômicas e sociais da região e influenciam os gastos com mão de obra, aquisição e transporte de insumos.

O custo elevado, em relação ao observado em outras regiões, explica-se também por esses projetos de reflorestamento estarem ainda numa fase de experimentação e definição da tecnologia a ser adotada. Assim sendo, esse processo gera uma baixa produtividade e, por consequência, um custo operacional maior que aqueles encontrados em outras regiões do Brasil.

Complementando, Resende et al. (2006) argumentam que os custos variam de caso para caso, considerando o reflorestamento em pequenas e médias propriedades, pois no caso de uso da mão de obra familiar há uma redução nos custos de implantação, uma vez que o custo de oportunidade desse fator, para o proprietário, pode ser menor que o praticado no mercado.

\section{Quantificação das receitas da atividade de reflorestamento}

Com base nas informações de preço da lenha em pé praticado no mercado local e na expectativa de volume produzido pelo povoamento, constatou-se que o projeto pode apresentar, no $7^{\circ}$ ano, a receita de $\mathrm{R} \$ 4.273,50$ por hectare.

\section{Avaliação da viabilidade econômica de povoamentos florestais em Rio Branco}

Os resultados econômicos do projeto em análise são apresentados e discutidos a seguir:

Valor presente líquido

A tabela 3 sintetiza o comportamento do valor presente líquido (VPL) do projeto de reflorestamento, sem a compra da terra e com a compra e venda da terra, em diferentes taxas de juros.

Tabela 3. Valor presente líquido com diferentes taxas de juros, do povoamento de eucalipto no Baixo Acre, estado do Acre, 2013.

Table 3. Net present value in different interest rates, of a eucalyptus plantation in Baixo Acre in the State of Acre, 2013.

\begin{tabular}{lcccc}
\hline VPL & $\mathbf{6 \%}$ a.a. & $\mathbf{8 \%}$ a.a. & $\mathbf{1 0 \%}$ a.a. & $\mathbf{1 2 \%}$ a.a. \\
\hline Sem a terra & $-4.574,67$ & $-4.855,36$ & $-5.093,72$ & $-5.296,41$ \\
Com a terra & $-6.249,38$ & $-6.937,91$ & $-7.527,93$ & $-8.034,66$ \\
\hline
\end{tabular}

Verifica-se, pelos valores indicados nessa tabela, que em todas as situações analisadas (segundo as diferentes taxas de juros, como também considerando ou não o custo com a terra) o VPL é negativo, indicando a inviabilidade desse tipo do projeto na região em questão.

Ao adotar a TMA de $6 \%$ (rendimento próximo à poupança), o investidor perde $\mathrm{R} \$ 4.574,67 / \mathrm{ha}$ com o projeto em questão, e se ele tiver de comprar a terra, há uma perda de R \$6.249,38/ha.

Vale mencionar que Goltz (2013), estudando a viabilidade do eucalipto para fins energéticos, verificou que, quando ocorreu a compra da terra, o VPL foi negativo e a TIR foi inferior ao custo de oportunidade do capital. Por outro lado, quando ocorreu o arrendamento da terra, o VPL foi positivo e a TIR ficou acima do custo de oportunidade do capital.

O VPL do projeto estudado se mostrou negativo em todas as taxas de juros consideradas. No entanto, na literatura se encontram trabalhos com povoamentos de eucalipto que oferecem rentabilidade compatível com outras atividades econômicas. A exemplo disso, Baena (2005) verificou que o manejo do eucalipto para celulose, com corte aos 6 e 12 anos de idade, apresentou um VPL de R\$1.085,94 e uma TIR de 18,88\%.

Pode-se atribuir o fraco desempenho econômico do povoamento de eucalipto em Rio Branco aos altos custos de produção quando comparado como de outras regiões, como também ao fato de a lenha ser um produto com baixo preço no mercado florestal. Tais afirmações se embasam na realidade de que o reflorestamento é ainda uma atividade praticamente desconhecida na região, de modo que os operários que nela atuam estão em fase de aprendizado, o que gera uma baixa produtividade operacional e, consequentemente, um custo maior de produção. Já a lenha tem um baixo preço no mercado florestal, pois tem-se, nessa região, uma significativa oferta desse produto, gerada como um subproduto do manejo florestal. Complementando, Bianquini (2008), analisando a rentabilidade de um povoamento de eucalipto, verificou que o sistema mais economicamente rentável foi aquele em que o 
destino da madeira atendeu uma multiplicidade de produtos (mourões, lenha e madeira para serraria), apresentando um lucro líquido 12,7 vezes maior quando comparado ao manejo da floresta para o uso exclusivo como lenha.

Taxa interna de retorno (TIR)

A taxa de desconto encontrada neste estudo foi de $-8,9 \%$ a.a. de retorno sem a compra e venda da terra. Por outro lado, ao considerar a compra da terra no ano 0 e venda da mesma no ano 7 , foi obtido uma taxa interna de retorno de $-4,62 \%$ a.a. Tem-se uma diferença na taxa interna de retorno de $-4,28 \%$ sem a terra e com a terra.

Em termos de renda, foi utilizado o valor de $\mathrm{R} \$ 15,00 / \mathrm{m}^{3}$, o qual representa o preço médio da madeira, para lenha, em pé na floresta, comercializada em Rio Branco no ano de 2015. Já o valor considerado para a compra e venda da terra foi de $\mathrm{R} \$ 5.000,00 /$ ha, que é o valor médio praticado no mercado imobiliário da região.

Valor esperado da terra (VET)

Na tabela 4 é apresentado o VET, ou seja, nas condições do projeto em questão, quanto o investidor pode pagar pela terra de acordo com a taxa de retorno esperada.

Tabela 4. Valor esperado da terra com diferentes taxas de juros, do povoamento de eucalipto no Baixo Acre, estado do Acre, 2013.

Table 4. Soil expectation value in different interest rates, of a eucalyptus plantation in Baixo Acre, in the State of Acre, 2013.

\begin{tabular}{lcccc}
\hline VET (R\$) & 6\% a.a. & $\mathbf{8 \%}$ a.a. & $\mathbf{1 0 \%}$ a.a. & $\mathbf{1 2 \%}$ a.a. \\
\hline & $-13.658,06$ & $-11.657,26$ & $-10.462,79$ & $-9.671,14$ \\
\hline
\end{tabular}

Os números indicados na tabela 4, apresentando o VET para todas as situações propostas, demonstram a inviabilidade do projeto. A título de ilustração, tem-se que o valor de compra (no ano zero) e venda da terra (no ano sete) no mercado imobiliário local é em média $\mathrm{R} \$ 5.000,00$ por hectare.

Vale (2004) verificou que o reflorestamento com eucalipto apresentou um VPL de R\$ 7.223,94, uma TIR de 24,8\% e um VET de R \$ 12.224,86, demonstrando assim a viabilidade do projeto analisado.

Souza Junior (2012), considerando uma taxa de 5\% ao ano, identificou um VET de R $26.009,98$ para o eucalipto de ciclo longo, $\mathrm{R} \$ 20.702,92$ para o eucalipto em propriedade familiar e $\mathrm{R} \$ 10.172,28$ para o eucalipto de ciclo curto.

Analise de sensibilidade

A tabela 5 indica o comportamento do VPL e da TIR com a redução dos custos de produção.

Tabela 5. Comportamento do VPL e da TIR com a redução dos custos de produção, Baixo Acre.

Table 5. NPV and IRR behavior with the reduction of production costs, in Baixo Acre.

\begin{tabular}{llllll}
\hline \multirow{2}{*}{ Custo (R\$/ha) } & \multicolumn{3}{c}{ VPL } & Taxa 12\% & TIR \\
\cline { 2 - 6 } & Taxa 6\% & Taxa 8\% & Taxa 10\% & $-7.423,19$ & $-3,87$ \\
\hline Menos 5\% & $-5.628,55$ & $-6.320,47$ & $-6.913,60$ & $-6.811,71$ & $-3,07$ \\
Menos 10\% & $-5.007,70$ & $-5.703,02$ & $-6.299,26$ & $-6200,23$ & $-2,23$ \\
Menos 15\% & $-4386,87$ & $-5085,58$ & $-5684,93$ & $-5.588,75$ & $-1,33$ \\
Menos 20\% & $-3.766,02$ & $-4.468,12$ & $-5.070,59$ & $-4.977,28$ & $-0,36$ \\
Menos 25\% & $-3.145,19$ & $-3.850,68$ & $-4.456,26$ & \\
\hline
\end{tabular}

Essa simulação demonstrou que, mantendo-se a receita constante ( $\mathrm{R} \$ 4.273,50)$, mesmo que o custo total por hectare (Custo Operacional + Terra) diminuísse 25\%, ou seja, chegasse a $\mathrm{R} \$ 9.497,24$, esse projeto continuaria sendo inviável.

A tabela 6 revela o comportamento do VPL e da TIR com o aumento da receita.

Tabela 6. Comportamento do VPL e da TIR com o aumento da receita.

Table 6. NPV and IRR behavior with the increase of wood price.

\begin{tabular}{lccccc}
\hline \multirow{2}{*}{ Preço $\left(\mathbf{R} \mathbf{\$} / \mathbf{m}^{\mathbf{3}}\right)$} & \multicolumn{3}{c}{ VPL } & Taxa 12\% & TIR \\
\cline { 2 - 6 } & Taxa 6\% & Taxa 8\% & Taxa 10\% & $-4,29$ \\
Mais 5\% & $-6.107,27$ & $-6.813,23$ & $-7.418,28$ & $-7.938,00$ & $-3,96$ \\
Mais 10\% & $-5.965,17$ & $-6.688,55$ & $-7.308,64$ & $-7.841,35$ & $-3,64$ \\
Mais 15\% & $-5.823,06$ & $-6.563,87$ & $-7.198,98$ & $-7.744,69$ & $-3,33$ \\
Mais 20\% & $-5.680,96$ & $-6.439,20$ & $-7.089,34$ & $-7.648,04$ & $-3,02$ \\
Mais 25\% & $-5.538,85$ & $-6.314,52$ & $-6.979,69$ & $-7.551,38$ & \\
\hline
\end{tabular}

FLORESTA, Curitiba, PR, v. 46, n. 3, p. 287 - 296, jul. / set. 2016.

Queiroz, A. M. de, Silva, Z. A. G. P. da G. e

ISSN eletrônico 1982-4688

DOI: $10.5380 /$ rf.v46i3.42931 
Essa simulação demonstrou que, mantendo-se os custos constantes, mesmo que a receita aumentasse $25 \%$, ou seja, se o preço de venda da madeira em pé chegasse a $\mathrm{R} \$ 18,75$ ou a produtividade chegasse a $356,12 \mathrm{~m} 3 / \mathrm{ha}$, esse projeto continuaria sendo inviável.

Quanto à possibilidade de aumento do preço de venda da madeira, Almeida (2010) relata que a formação do preço depende principalmente dos custos de produção, mas é o mercado quem geralmente determina ou estabelece esse preço, resultante do equilíbrio entre as forças de oferta e demanda.

Carmo et al. (2011), estudando os custos de implantação de eucalipto no Espírito Santo em espaçamento de 3,0 × 3,0 m, identificou um custo total de $\mathrm{R} \$ 3.774,52 / \mathrm{ha}$ em um horizonte de seis anos. Ao fazer a análise financeira do projeto, concluiu que ele apresentou VPL positivo apenas para uma produtividade acima de 145,51 m³ ha. Complementarmente a isso, Resende et al. (2004) encontraram VPL positivo efetivo a partir da produtividade de eucalipto de $133,60 \mathrm{~m}^{3} / \mathrm{ha}$.

\section{CONCLUSÕES}

Os resultados gerados no presente estudo permitem inferir que:

- Os projetos analisados apresentaram um elevado custo de implantação e manutenção quando comparados com os custos encontrados em outros estudos.

- Os reflorestamentos avaliados geraram uma renda menor que as obtidas em projetos similares implantados em outras regiões do Brasil.

- Os povoamentos pesquisados demonstram que, nas condições propostas, produzir eucalipto para atender à geração de energia em Rio Branco não oferece viabilidade superior ao custo de oportunidade do capital, indicando assim a inviabilidade econômica dessa atividade.

\section{REFERÊNCIAS}

ACRE. Secretaria de Estado de Meio Ambiente. Zoneamento ecológico-econômico do Estado do Acre, fase II: Documento Síntese. Rio Branco, 2010. 356 p.

ASSOCIAÇÃO BRASILEIRA DE FLORESTAS PLANTADAS (ABRAF). Anuário Estatístico da ABRAF: Ano base 2012. Brasília, 2013, 145 p.

BAENA, E. S. A rentabilidade econômica da cultura do eucalipto e sua contribuição ao agronegócio brasileiro. Revista Conhecimento Interativo, São José dos Pinhais, v. 1, n. 1, p. 3-9, 2005.

BENTES-GAMA, M. M. Orientações para pesquisa florestal em Rondônia. Porto Velho: Embrapa Rondônia, 2005. 4 p. (Comunicado Técnico, n. 290).

BERGER, R.; GARLIPP, R. C. Custo-preço: uma alternativa financeira na avaliação da produção florestal. São Paulo: IPEF. Circular Técnica, n. 141, 1982.

BERGER, R.; TIMOFEICZYK JUNIOR, R.; LACOWICZ, P. G.; BRASIL, A. A. Análise econômica da industrialização primária da madeira na região Amazônica. Revista Floresta e Ambiente. Seropédica, v. 9, n. 1, p. 9-17, 2002

BERGER, R.; SANTOS, A. J.; TIMOFEICZYK JUNIOR, R.; BITENCOURT, A. M.; SOUZA, V. S.; EISFELD, C. L. O efeito do custo da terra na rentabilidade florestal: um estudo de caso para Santa Catarina. Revista Floresta, Curitiba, v. 41, n. 3, p. 599-610, 2011.

BIANQUINI, L. A. Analise de custo e receita de povoamento de Eucalyptus grandis submetido a dois regimes de manejo: Estudo de caso em propriedade rural na Zona da Mata mineira. 2008. 49 f. Monografia (Graduação em Engenharia Florestal) - Instituto de Florestas, Universidade Federal do Rio de Janeiro, Seropédica, 2008.

BRASIL. Ministério da Agricultura, Pecuária e Abastecimento. Cadeia produtiva de madeira. Série Agronegócios: v. 6. Brasília, 2007. 84 p.

CARMO, F. C. de A.; FIEDLER, N. C.; GUIMARÃES, P. P.; PEREIRA, D. P.; ANDRADE, W. S. de P. Análise de custos da implantação de cultivos de eucalipto em áreas acidentadas no sul do Espírito Santo. Cerne, Lavras, v. 17, n. 4, p. 473-479, 2011.

FERNANDES, L. M. Estudo da rentabilidade e risco da produção de eucalipto para energia em Minas Gerais. Informações Econômicas, São Paulo, v. 43, n. 6, 2013. 
FERREIRA, C. A.; SILVA, H. D. Eucalyptus para a região amazônica, estados de Rondônia e Acre. Colombo: Embrapa Florestas, 2004. 4p. (Comunicado Técnico 116).

FIEDLER, N. C.; CARMO, F. C. A.; PEREIRA, D. P.; GUIMARÃES, P. P.; RÓS, E. B.; MARIN, H. B. Viabilidade técnica e econômica de plantios comerciais em áreas acidentadas no sul do Espírito Santo. Ciência Florestal, Santa Maria, v. 21, n. 4, p. 745-753, 2011.

FISHER, A.; ZYLBERSZTAJN, D. O fomento florestal como alternativa de suprimento de matéria-prima na indústria brasileira de celulose. Revista Eletrônica de Administração. Porto Alegre, ed. 72, n. 2, p. 494-520, maio/ago. 2012.

GOLTZ, V. Viabilidade econômica para a implantação de cultivo de eucalipto para fins energéticos na Seara Indústria e Comércio de Produtos Agropecuários LTDA. 2013. 38 f. Dissertação (Mestrado em Ciência e Tecnologia de Sementes) - Programa de Pós-Graduação em Ciência e Tecnologia de Sementes, Universidade Federal de Pelotas, Pelotas, 2013.

KARLING, S. Viabilidade de produção de Pinus em áreas ociosas nas propriedades rurais da região centro-sul paranaense. 66 f. 2004. Dissertação (Mestrado em Engenharia Florestal) - Curso de Pós-Graduação em Engenharia Florestal, Universidade Federal do Paraná, Curitiba, 2004.

KLEMPERER, W. D. Capital budgeting in forestry. In: KLEMPERER, W. D. Forest resource economics and finance. New York: McGraw-Hill, Inc, 1996. p. 169-201.

LIMA JUNIOR, V. B.; REZENDE, J. L. P.; OLIVEIRA, A. D. Determinação da taxa de desconto a ser usada na análise econômica de projetos florestais. Cerne, Lavras, n. 1, p. 45-66, 1997.

MELIDO, R. C. N. Avaliação técnica e econômica de dois projetos florestais com eucalipto para fins energéticos. 62 f. 2012. Dissertação (Mestrado) - Curso de Pós-Graduação em Ciências Florestais, Universidade de Brasília. Brasília, 2012.

POGGIANI, F. Ecologia e reflorestamento. Piracicaba: IPEF. Circular Técnica, n. 61, 1979.

RAPASSI, R. M. A.; TARSIANO, M. A. A.; PEREIRA, J. C. R.; ARAÚJO, C. A. M. Cultura do eucalipto na região de Suzanápolis, estado de São Paulo: análise econômica. Informações Econômicas, São Paulo, v. 38, n. 4, 2008.

REZENDE, J. L. P.; PÁDUA, C. T. J.; OLIVEIRA, A. D. de; SCOLFORO, J. R. S. Análise econômica de fomento florestal com eucalipto no estado de Minas Gerais. Cerne, v. 12, n. 3, p. 221-231, 2006.

REZENDE, J. L. P.; OLIVEIRA, A. D. Análise econômica e social de projetos florestais. 2. ed. Viçosa: UFV, 2008. 386 p.

SAGUINO, A. C. Custos de implantação e rentabilidade econômica de povoamentos florestais com teca no estado do Pará. Revista Ciências Agrárias, Belém, n. 52, p. 61-78, 2009.

SANT'ANNA, A. G.; LEONEL, M. S. Projeto de viabilidade: a importância da avaliação de projetos florestais para produtores rurais. Unimontes Científica, Montes Claros, v. 11, n. 1/2, 2009.

SILVA, K. R.; MINETTI, L. J.; FIEDLER, N. C.; VENTUROLI, F.; MACHADO, E. G. B.; SOUZA, A. P. de. Custos e rendimentos operacionais de um plantio de eucalipto em região de cerrado. Revista Árvore, Viçosa, v. 28, n. 3, p. 361-366, 2004.

SILVA, M. L.; FONTES, A. A. Discussão sobre os critérios de avaliação econômica: valor presente líquido (VPL), valor anual equivalente (VAE) e valor esperado da terra (VET). Revista Árvore, Viçosa, v. 29, n. 6, p. 931-936, 2005.

SOUZA JUNIOR, J. O. Analise econômica em plantios de pinus e eucalipto no planalto serrano catarinense. 174 f. 2012 Dissertação (Mestrado em Engenharia Florestal) - Curso de Pós-Graduação em Engenharia Florestal, Universidade Federal do Paraná, Curitiba, 2012.

VALE, R. S. Agrossilvicultura com eucalipto como alternativa para o desenvolvimento sustentável da Zona da Mata de Minas Gerais. 2004. 115 f. Tese (Doutorado em Ciência Florestal) - Programa de PósGraduação em Ciência Florestal, Universidade Federal de Viçosa, Viçosa, 2004. 